Proc. Indian Acad. Sci. (Chem. Sci.), Vol. 89, Number 2, April 1980, pp. 153-161. (C) Printed in India.

\title{
Conductance studies on the interaction of $D$-glucose with alkali halides in water and formamide
}

\author{
VISHNU and VIDYA SAGAR MISHRA* \\ Department of Chemistry, University of Gorakhpur, Gorakhpur 273001 , India \\ * Department of Chemistry, Shri Murli Manohar Town Post-Graduate Colloge, \\ Ballia 277 001, India \\ MS received 17 May 1979; revised 18 Docember 1979

\begin{abstract}
The interaction of D-glucose with alkali halide in aqueous and formamide solutions has been studied by employing conductance measurements. Our results showed a break at the saturation temperature indicating a transition in the conductance values. This behaviour is explained in terms of solute-solvent interactions involved in the electrolyte-solvent-nonelectrolyte systems.
\end{abstract}

Keywords. Alkali halides; formamide solution; conductance studies; D-glucose.

\section{Introduction}

Studies on structural interactions in ternary systems comprising electroly te-solvents nonelectrolyte, by physico-chemical techniques have been the subject of activeresearch in recent years. The conductance of electrolytes in the presence of nonelectrolytes have been measured by several workers (Longsworth 1947; Steel et al 1958; Fredricksson 1969). The inability of the Walden rule or the Stokes law (Robinson and Stokes 1965) to interpret these results has been attributed to the interaction of the nonelectrolyte with the ions of the electrolyte (Fredricksson 1969; Fisher and Koval 1939; Hale and De Vries 1948). Nonelectrolytes like polyhydroxy compounds interact with electrolytes in solution (Longsworth 1947; Fredericksson 1969). Definite adducts of many carbohydrates with salts and hydrated oxides of alkali and alkaline-earth metals have also been reported (Rendleman 1966; Moulik 1973). Equations relating the conductance of nonhydrated and hydrated insulator-type bodies (including several proteins and polyhydroxy compounds) have been obtained by Moulik $(1972,1973)$ and the change in conductance values has been attributed to the obstruction of the electrical migration of ions by the environmental nonelectrolyte entities. Similar significant changes in conductance of carbohydrate-electrolyte solutions were also reported by Moulik and Mitra (1973) who have also obtained association constant values for D-glucose and sucrose solutions. 
It has been shown earlier by Vishnu and Singh $(1974,1975)$ that an abrupt transition oscurs in the conductance values of homogeneous ' electrolyte-solvent-nonelestrolyte' systems when the solution passes through the saturation temperature as it is cooled from the unsaturated to the super-saturated state, and pairs of straight lines intersesting one another at saturation temperature are obtained, when the values of $-\log K$ for these systems are plotted against their absolute temperature resiprosal values $(1 / T)$. The divergence of the pairs of straight lines is also influenced by the structure-making and breaking properties of the solutes.

In the present paper, D-glucose, a monosaccharide, having five hydrogen bonding sites and which can interast with electrolytes in solution has been chosen as a typical nonelectrolyte for our studies. These studies have been conducted in water and in formamide, the latter being structured, polar solvent of very high dielectric constant $\left(109 \cdot 5\right.$ at $\left.25^{\circ}\right)$.

\section{Experimental}

\subsection{Materials}

Analytical reagent grade samples of $\mathrm{NaCl}, \mathrm{NaBr}, \mathrm{NaI}, \mathrm{KCl}, \mathrm{KBr}, \mathrm{KI}$ and $\mathrm{D}$-glucose obtained from $\mathrm{BDH}$ and $\mathrm{E}$ Merck, were employed and used without further purification. Formamide obtained from BDH (England) was kept overnight over freshly ignited quicklime and distilled under reduced pressure. The middle fraction of the distillate was collested. The process of purification was repeated until the elestrical conductance of the sample was reduced to about $10^{-5}$ mho or less.

\subsection{Measurements}

A suitably grounded Leeds and Northrup Kohlrausch slide wire assembly was used for conductance measurements. Tubular conductivity cells, temperature control and other experimental procedures were described earlier (Vishnu and Singh 1974).

The solutions were prepared by weight, in doubly distilled, demineralised, conductivity water (sp. conductivity $\sim 10^{-6} \mathrm{ohm}^{-1} \mathrm{~cm}^{-1}$ ) and in pure formamide. A $0.1 \mathrm{M}$ solution of the electrolyte was prepared and saturated with $\mathrm{D}$-glucose at $50.0 \pm 0.05^{\circ}$ in an oil thermostat for 20 to $30 \mathrm{hr}$. Crystals from the mother liquor were completely separated by elestric centrifugation within an air thermostat maintained at the same temperature $\left(50.0 \pm 0.02^{\circ}\right)$. The centrifugate was transferred to a conductivity cell kept at the same temperature within the air thermostat. The cell was then immersed in the constant temperature oil bath maintained at a higher temperature $\left(65-70^{\circ} \mathrm{C}\right)$. The resistance of the experimental solution was first measured at the highest temperature. The temperature was then lowered between 2 and $4^{\circ}$ at a time and maintained for at least $30-40 \mathrm{~min}$, before the resistance was measured at 20 to $25^{\circ}$ above and below the saturation temperature. Before each measurement, no crystallisation was allowed to occur in the cell solution.

\section{Results and discussion}

Negative logarithm of the specific conductance values $(-\log K)$ of sodium and potassium halides in water and formamide solutions saturated with $D$-glucose at 
$50^{\circ}$ plotted against the resiprocal of the absolute temperature $(1 / T)$ are shown in figures 1 and 2 . Figures 3 and 4 give the deviation values, against $1 / T$ values for these systems. The deviation values were obtained with least-square calculations. For this purpose, the best fit for the points above the saturation temperature was obtained statistically, and the theoretial values of $-\log K$ were obtained from the regression equation for different values of $1 / T$. The difference between the observed values of $-\log \mathrm{K}$ and the calculated values are termed deviations. The plots in figures 1 and 2 consisted of two straight lines intersecting in the vicinity of the saturation temperature (Vishnu and Singh 1974, 1975, 1977b). The divergence of the pairs of straight lines is markedly influenced by the cation and anions of different sizes in both water and formamide solvents. The divergence of the two straight lines in formamide solution is less than that of the aqueous solutions.

The trend of deviation of the pairs of straight lines (figure 3a) follow the order $\mathrm{NaI}>\mathrm{NaBr}>\mathrm{NaCl}$ for sodium halides-glucose-water systems while for potassium halides-glucose-water system the deviation is more or less of the same order (figure 3a), i.e., the points fall on a single straight line irrespective of the nature of

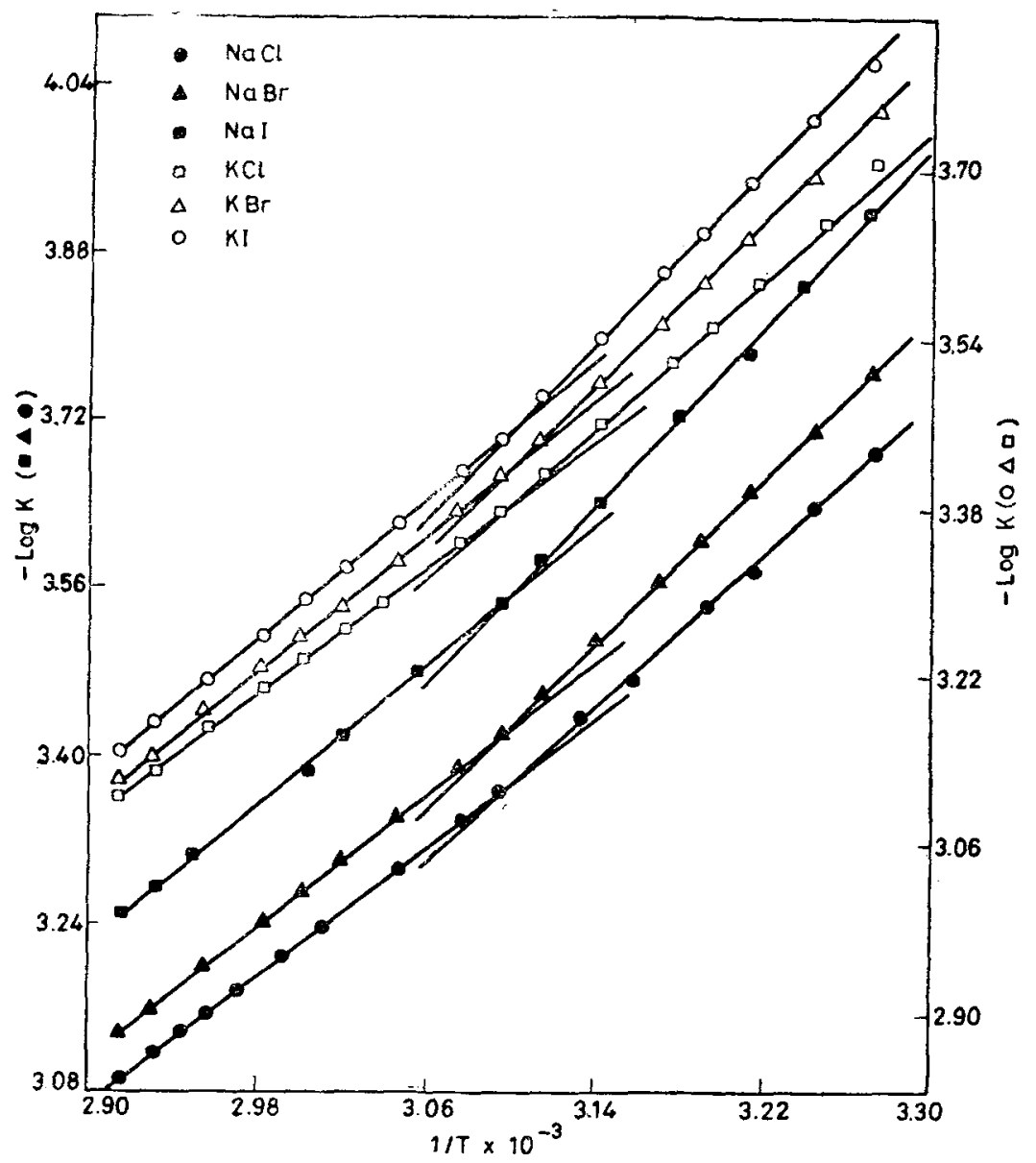

Figure 1. Plots of $-\log K$ versus $1 / T$ for alkali halides-glucose-system. 


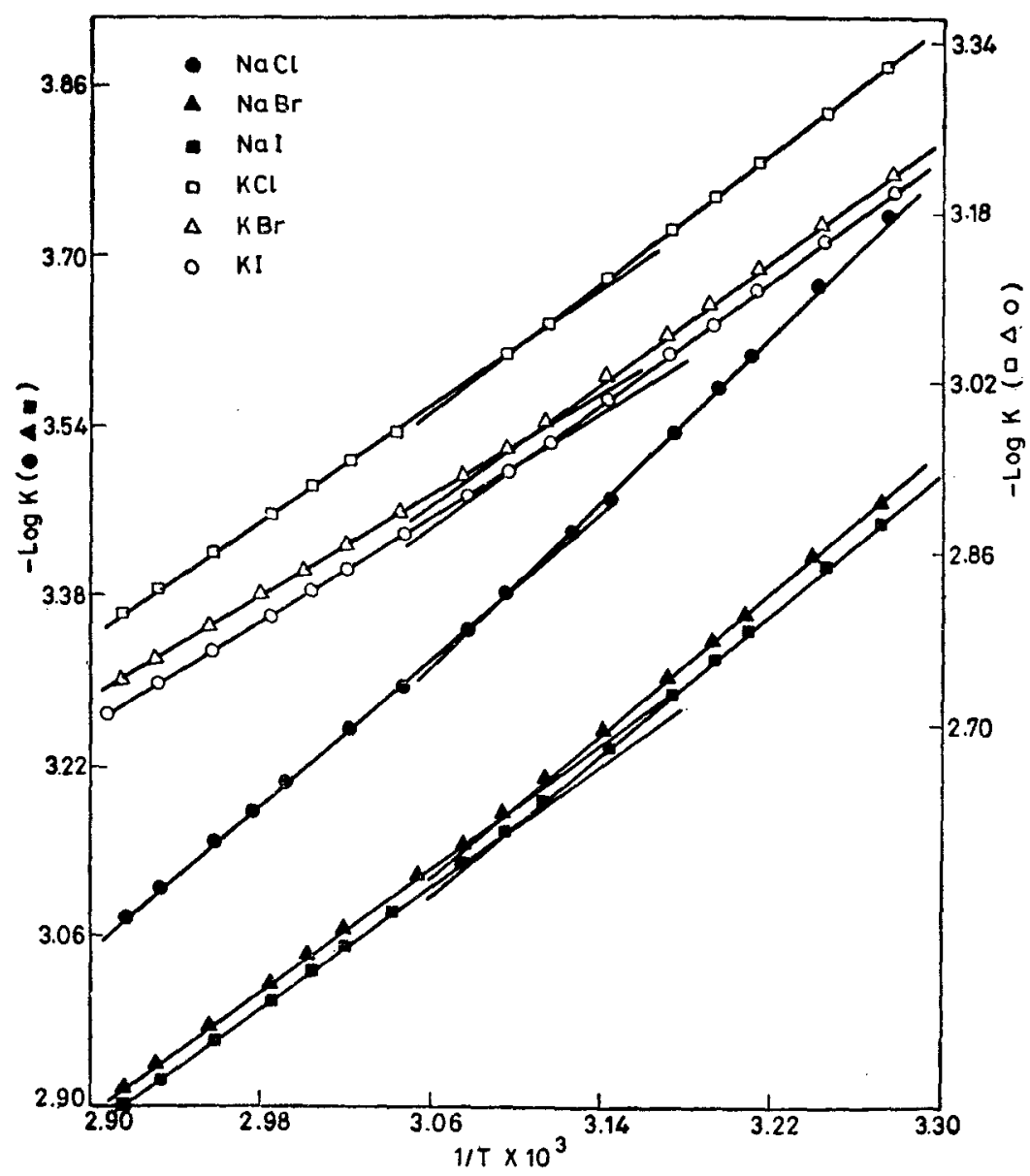

Figure 2. Plots of $-\log K$ versus $1 / T$ for alkali halides-glucose-formamide system

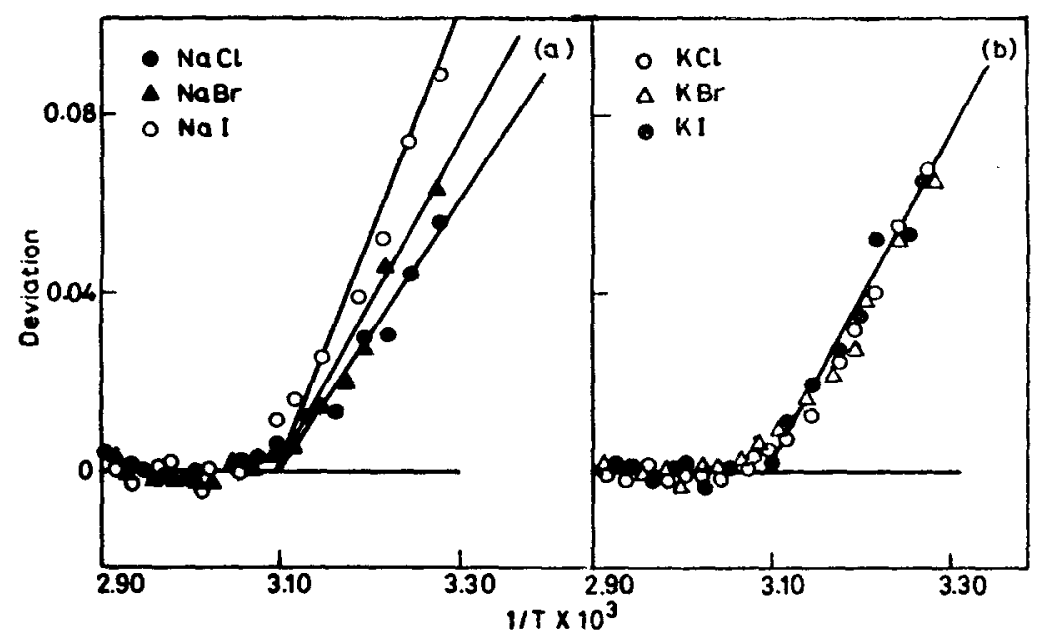

Figure 3. (a) Deviation plots for the sodium halides-glucose-water system, (b) Deviation plots for the potassium halides-glucose-water system. 


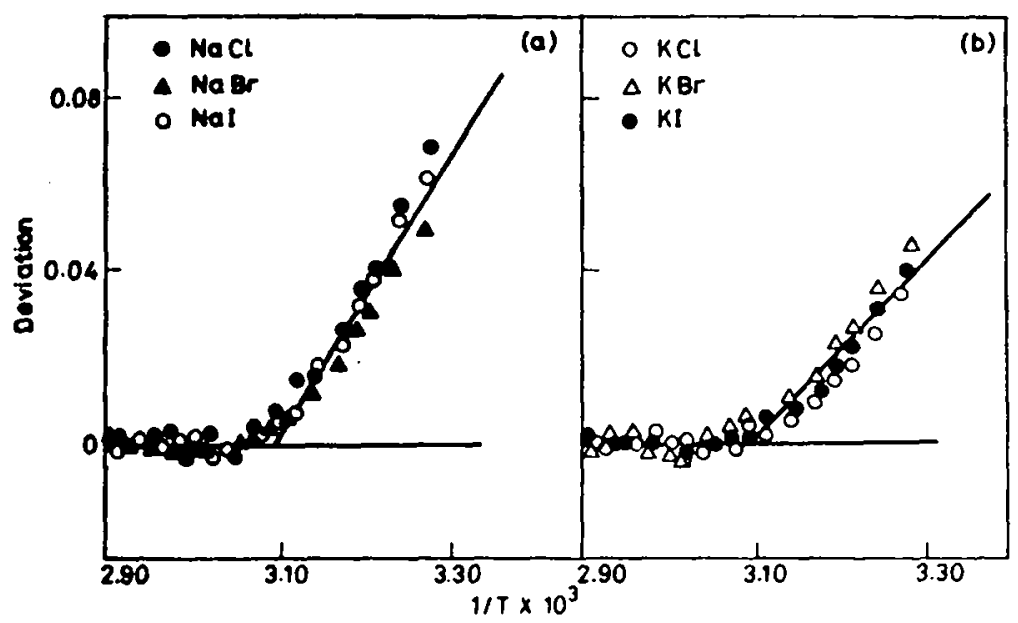

Figure 4. (a) Deviation plots for the sodium halides-glucose-formamide system. (b) Deviation plots for the potassium halides-glucose-formamide system.

the halide ions. It has also been observed that the deviation is larger in the case of sodium halides in glucose-water system than the potassium halides (figures $3 \mathrm{a}$ and $3 b$ ) for the above system.

The hydration of several polyhydroxy compounds and their aggregation with water has been obtained by analysing the viscosity data of their aqueous solutions (Moulik and Khan 1977). The hydration properties of the D-glucose, which has $5 \mathrm{OH}$ groups, are not related to the number of $\mathrm{OH}$ groups or oxygen atoms in the molecule, probably the result of the conformation which the D-glucose adopts in aqueous solution (Tait et al 1972). It has been shown (Angyl 1969) that Dglucose has $\mathrm{C} 1$ conformation. The majority of the $\mathrm{OH}$ groups are in an equatorial configuration and the distance between the groups in this configuration or the same side of the ring, e.g., OH groups attached to carbon atoms 1,3 and 5 of $\beta$-D-glucose is $4.86 \AA$ (Warner 1962). This agrees with the second nearest neighbour distance in water of $4.9 \AA$ (Danford and Levy 1962) which is derived from the $x$-ray data for water assuming a tetrahedral structure, and supports the proposal that hydrogen bonding would be expected between water and the D-glucose $\mathrm{OH}$ groups (Kabayama et al 1958). Experiment reveals that D-glucose forms a stable monohydrate in aqueous solution (Tait et al 1972) which has been isolated having melting point $83^{\circ} \mathrm{C}$ (Heilbon and Bunbury 1965). The pyranose form of D-glucose is therefore stabilised by the interaction with water (Lemieux and Stevens 1966; Angyal 1969) and the NMR measurements of Tait and others provide evidence for the greater hydration of the 6-membered ring conformation in D-glucose and offer a description of the nature of the hydrophilic interactions. In proton magnetic relaxation studies of D-glucose in $\mathrm{D}_{2} \mathrm{O}$ (Suggett 1976) one proton ( $H 1$ in the $a$-form only) is susceptible to intermolecular proton-proton interactions while the remaining protons are very effectively shielded. This is consistent with the conformational and hydration properties of D-glucose.

By measuring the conductance of various electrolytes in solutions of D-glucose and sucrose, the hydration of these compounds and their association with electro- 
lytes have been examined and it was found that both D-glucose and sucrose complex assosiate with the electrolytes (Moulik and Khan 1974). It had earlier been established that the deviations produced in electrolyte-solvent-nonelectrolyte ternary systems increases with increase in the structure-breaking properties of electrolytes (Vishnu and Singh 1974). The greater deviation values observed with alkali halides in glucose-water system than in sucrose-water reveals that D-glucose is a less structure-maker in electrolyte-solvent-nonelectrolyte system than sucrose. It is known that sucrose has 8 hydrogen bonding groups possessing two intramolecular H-bonds involving the two hydroxy methyl groups of the furano residue and side the ring 0 (5) and the hydroxyl 0 (2) of the pyranoside residue, as previously reported (Vishnu and Singh 1974).

Figures $3 a$ and $3 b$ indicate that the deviations are more pronounced in $\mathrm{Na}^{+}$ions than $\mathrm{K}^{+}$ions for alkali halides-glucose-water systems, and thus the structuremaking properties of $\mathrm{Na}^{+}$ions and the structure-breaking properties of $\mathrm{K}^{+}$ions are effectively perturbed. As a result the $\mathrm{Na}^{+}$ions act as a less structure-maker in glucose-water system than $\mathrm{K}^{+}$ions and the anionic deviation trend for the above cation follow the order $\mathrm{I}^{-}>\mathrm{Br}^{-}>\mathrm{Cl}^{-}$. The similar deviation for potassium halides in the potassium halides-glucose-water system (figure $3 b$ ) may be due to the smaller structure-breaking properties of $\mathrm{K}^{+}, \mathrm{Cl}^{-}, \mathrm{Br}^{-}$and $\mathrm{I}^{-}$ions in $\mathrm{D}$-glucose solution.

Our results could be explained by comparing the work of Frank and his associates (Frank and Evans 1945, Frank and Wen 1957, Frank 1965) who examined the effects of solute on the structure of water. In solution, nonelectrolytes like D-glucose may act as insulator to the permeating electric current which conducts the ions of the electrolytes (Moulik 1972). Association of many ions with nonelectrolytes (Fredricksson 1969; Fisher and Koval 1939; Hale and De Vries 1948) may further reduce their migration. The ion-nonelectrolyte association could be mainly responsible for the large decrease of the conductance values of alkali halides in D-glucose. Steel et al (1958) observed that the ionic mobility. decreases in the presence of several polyhydroxy compounds. It has also been observed by Moulik and Mitra $(1971,1973)$ that D-glucose binds the electrolytes of greater charge density more strongly than sucrose even though the hydrogen bonding sites in sucrose are greater (8) than D-glucose (5). The probable reaction scheme may be depicted as following-

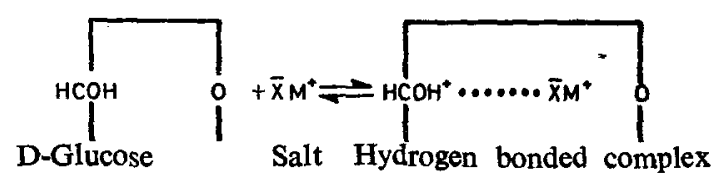

where $\mathrm{M}^{+}$is a metal ion and $x^{-}$is its counter ion.

This clearly indicates that in D-glucose solution the mobility of $\mathrm{Na}^{+}$ions is slower than $K^{+}$ions contrary to the behaviour of these ions in pure water.

The transport property is also affected by the interaction between solvent water and ionised groups as well as by the ordered structure of water around the nonpolar groups (Uedaria and Uedaira 1964, 1965). The water molecule in the immediate vicinity of non-polar group like $\mathrm{D}$-glucose becomes less mobile than pure water. In other words, the entropy of the aqueous D-glucose solution is less than pure 
water. The interaction of the ions with the solvent molecules further affects the entropy of the system. The system undergoes a change in entropy due to change in the bulk structure as a result of molecular rearrangement of a higher order, i.e., a decrease in entropy. This decrease is similar to that noted for supercooled liquids (Kauzmann 1948). In the present study, as the system passes from an unsaturated to a supersaturated state through the saturation temperature, the decrease in entropy results in a change of the molecular geometry of glucose-water molecular assembly bringing about a change in the structure of D-glucose as well as water, thus affesting the equilibrium between $a$ - and $\beta$-anomers of D-glucose. In the unsaturated state the D-glucose is mostly in the $\beta$-form while in the supersaturated state the $a$-anomer may predominate. The change from unsaturated to supersaturated state is brought about by a change from $\beta$-anomer to $a$-anomer through the formation of a cyclic transition complex of the $a$-anomer of D-glucose which is heavily hydrated. Addition of metal ions shifts the position of the $\alpha$ - and $\beta$ anomers equilibrium towards the formation of more of $a$-anomer (Finar 1975), thus permitting a hydration geometry which is in its molecular spacings and orientation almost compatible with those regarded as characteristics of liquid water. Such a hydration state could therefore be formed with a minimum of perturbation in the hydrogen bonding pattern of water. The presence of jons also affect this equilibrium by associating with $a$-anomer of D-glucose (Finar 1975), which in turn affects the mobility of ions in the supersaturated state and a decrease in the conductance value. Thus the solute-solvent interactions play an important role as compared to solute-solute interaction. However there is no evidence for the self assosiation of D-glucose molecules in aqueous electrolyte solutions. The hydration of $\mathbf{D}$-glucose molecule and the change in the solvent structure brought about by the ions as well as the D-glucose molecules is mainly responsible for the change in the conductance value. This change is sensitive to rationalise the molecular interaction occurring in these ternary systems. Thus the deviation is greater for $\mathrm{Na}^{+}$ions than $\mathrm{K}^{+}$ions as well as an anionic effect in potassium halides-glucosewater systems showing a difference in the structural interactions for the various ions.

Deviation plots (figures $4 a$ and $4 b$ ) for the electrolyte-glucose-formamide system show a greater deviation in sodium halides than potassium halides in glucoseformamide. The explanation of this is similar to that of glucose-water system because formamide is a protic solvent having comparable $\mathrm{H}$-bonding capabilities to that of water (Thomas and Evans 1970) and possesses similar physical properties to that of water (Vishnu and Singh 1975). One may therefore expect a similarity in the structural behaviour of D-glucose in both the solvents.

Further, the greater deviation values observed in sodium and potassium-halideglucose-water indicate that $\mathbf{D}$-glucose is less structure-maker in water-electrolyte system than in formamide-electrolyte system. These results could also be explained by calculating the activation energies of the alkali halide-glucose systems in water and formamide solutions. Table 1 gives the activation energies of conduction for each straight line computed from the Arrhenius plots ( $-\log K$ vs $1 / T$ ).

The transition in conductance values of the alkali halide-glucose systems in water and formamide has been taken in terms of different activation energies for supersaturated and unsaturated regions and the differences in the activation energies of the two homogeneous processes, termed as activation energies of transition 
Table 1. Activation energy change $(\Delta E)$ at saturation temperature $\left(50^{\circ}\right)$ for $1: 1$ electrolytes in 'D-glucose-water' and 'D-glucose-formamide' systems.

\begin{tabular}{llc}
\hline \multirow{2}{*}{ Electrolytes } & \multicolumn{2}{c}{$\Delta E\left(K J M^{-1}\right)$} \\
\cline { 2 - 3 } & $\begin{array}{c}\text { D-glucose- } \\
\text { water }\end{array}$ & $\begin{array}{c}\text { D-glucose- } \\
\text { formamide }\end{array}$ \\
& & \\
$\mathrm{NaCl}$ & $5 \cdot 323$ & $4 \cdot 255$ \\
$\mathrm{NaBr}$ & $6 \cdot 835$ & $4 \cdot 786$ \\
$\mathrm{NaI}$ & 7.645 & $5 \cdot 698$ \\
$\mathrm{KCl}$ & 3.979 & 3.804 \\
$\mathrm{KBr}$ & 5.059 & 4.687 \\
$\mathrm{KI}$ & 6.576 & 5.053 \\
\hline
\end{tabular}

$(\triangle E)$, has been attributed to the change in the solvent structure due to the presence of electrolytes and nonelectrolytes with many hydrogen-bonding sites at saturation concentration.

D-glucose molecules with five hydrogen bonding sites adhere the water as well as formamide molecules and form a bigger cluster near the ionic solutes. In supersaturated solution, these bigger structures are easily approached by the structuremaking/breaking properties of ions and this is the reason for the difference in $\triangle E$ for different ions.

It is evident from table 1 that $\triangle E$ values for D-glucose-water systems are greater than those obtained for D-glucose-formamide systems of the corresponding ions. This is probably because D-glucose is less structure-maker in water-electrolyte than in formamide-electrolyte systems, which further supports the lesser deviation observed in D-glucose-formamide than D-glucose-water systems with alkali halides. The $\triangle E$ values for sodium halides are higher than potassium halides in D-glucose-water and D-glucose-formamide systems, which strongly supports the less structure-making tendencies as well as the higher deviations of sodium halide than potassium halides in D-glucose-water and D-glucose-formamide systems.

\section{Acknowledgements}

Thanks are due to Prof. R P Rastogi for providing laboratory facilities and the University Grants Commission, New Delhi, for financial assistance to VSM. The authors are also thankful to the referee for useful comments.

\section{References}

Angyal S J 1969 Angew. Chem. Int. Ed. Engl. 8157

Bull H B, Breese K, Ferguson G L and Swenson C A 1964 Arch. Biochem. Biophys. 104297

Danford M D and Levy H A 1962 J. Am. Chem. Soc. 843965

Heilbon S T and Bunbury H N 1965 Dictionary of organic conpounds (London: Eyre and Spottiswoode) 3 cited from Tait et al 1972. 
Finar I L 1975 Organic chemistry 5th ed. (London: Longman Group) 2304

Fisher P Z and Koval T E 1939 Bull. Sci. Rec. Chim. 4137

Frank H S and Evans M W 1945 J. Chem. Phys. 13507

Frank H S and Wen W Y 1957 Disc. Faraday Soc. 24133

Frank H S 1965 Fed. Proc. 5241

Fredricksson S 1969 Acta Chem. Scand. 231993

Hale C H and De Vries D E $1948 \mathrm{~J}$. Am. Chem. Soc. 702473

Kabayama M A, Patterson D and Piche L 1958 Can. J. Chem. 36557

Kauzmann W 1948 Chem. Rev. 43219

Lemienx R V and Stevens J D 1966 Can. J. Chem. 44249

Longsworth L G 1947 J. Am. Chem. Soc. 691288

Moulik S P 1972 Electrochim Acta 171491

Moulik S P 1973 Electrochim. Acta 18981

Moulik S P and Khan D P 1974 Carbohydr. Res. 36147

Moulik S P and Mitra A K 1971 Carbohydr. Res. 19416

Moulik S P and Mitra A K 1973 Carbohydr. Res. 28371

Moulik S P and Mitra A K 1973 Carbohydr. Res. 29509

Moulik S P and Khan D P 1977 Indian J. Chem. A15 267

Rendleman J A 1966 J. Adv. Carbohydr. Chem. 21209

Robinson R A and Stokes R H 1965 Electrolyte solutions 2nd ed. (London: Butterworths)

Steel B J, Stokes J M and Stokes R H 1968 J. Phys. Chem. 621514

Suggett A 1976 J. Solution Chem. 533

Tait M J, Ablett S and Franks F 1972 Water-structure at the water-polymer interface (New York: Plenum Press) p. 34

Thomas J and Evans D F 1970 J. Phys. Chem. 743812

Uedaria H and Uedaira H 1964 Bull. Chem. Soc. Jpn. 371885

Uedaria H and Uedaira H 1965 Bull. Chem. Soc. Jpn. 382194

Vishnu and Singh A K 1974 Proc. Indian Acad. Sci. A80 57

Vishnu and Singh A K 1975 Proc. Indian Acad. Sci. A81 220

Vishnu and Singh A K 1977a Carbohydr. Res. 54149

Vishnu and Singh A K 1977b Carbohydr. Res. 58 307, 316

Vishnu and Singh A K 1978 Proc. Indian Acad. Sci. A87 121

Warner D T 1962 Nature (London) 1961055 